\title{
Independent clinical investigation in Europe: an endangered species
}

On the $1^{\text {st }}$ of May 2001, the Official Bulletin of the European Community published the Directive 2001/20/CE relating to Good Clinical Practice (GCP) in the conduct of clinical trials involving medications ${ }^{1}$. In Article 22, the Directive stated that the member states must adopt and publish their legal statutes, laws and administrative structures necessary to fulfil the stated Directive; action which is still pending in the majority of European states but whose final date of implementation is the $1^{\text {st }}$ May 2004. There is no doubt that a Directive such as this, which seeks to introduce uniformity in the conduct of clinical investigation in Europe and which will scrupulously guarantee the rights of the patients incorporated in trials, is not only convenient but also necessary and, in this sense, deserves the highest support. However, some of the clauses introduce requirements that are difficult to achieve on the part of the Independent Investigator within the current Spanish and European setting.

As discussed in the special article published in this current issue of the Revista de Oncología ${ }^{2}$, this Directive, in its Article 1, defines medication under investigation as: "pharmaceutical preparation of an active substance, or placebo, that is being investigated or is used as reference in a clinical trial, including products with commercial authorisation when used in a combination (in the preparation or in the packaging) different from what has been authorised, or when used for the treatment of a clinical indication that has not been authorised, or to obtain more information on its authorised use». As such, in clinical practice, all the drugs used in a prospective study will be considered as medications under investigation, independently of whether or not they have been authorised for the clinical indications for which they are being investigated. Similarly, in Article 19, Paragraph 2, it is stated that «Unless Member States have established precise conditions for exceptional circumstances, investigational medicinal products and, as the case may be, the devices used for their administration shall be made available free of charge by the sponsor».

In the initial version which had been distributed for comment/suggestions to the Pharmaceutical Industry and representatives of Ethics Committees (but not to Individual Investigators nor to Co-operative Research Groups) the Spanish Administration had not considered establishing any single condition that may be con- sidered necessary for application to exceptional cases of special circumstances. The French and the Belgian Administrations, conversely, have established precise conditions for trials sponsored by Co-operative Groups and by Independent Investigators.

As can be learnt from the current version, this Directive would appear to reduce drastically (if not abolish) the possibility of conducting clinical trials sponsored by Independent Investigators or Co-operative Groups in our country (and probably in many other European countries). This Directive appears to focus exclusively on the registration of new pharmaceutical products in studies sponsored by the Pharmaceutical Industry. The requirement that the sponsor provide all the medications involved in the clinical trial completely changes the setting of academic clinical investigation that has existed in our country, up to now. Todate, Independent Investigators and Co-operative Groups could conduct clinical trials with pharmaceutical products approved for an indication without having to provide the medications, provided that the said trials are performed in the same indications for which the medication has been approved. In these cases, in our country, the Public Healthcare System (PHS) provides the medications for the trial. Two trials promoted by the GEICAM group serve to illustrate this situation. The GEICAM 9401 trial $^{3}$ comparing two different ways of administration (sequential versus concomitant) of EC (epirubicin plus cyclophosphamide) and tamoxifen as adjuvant therapy in post-menopausal women. It was not known whether there was an interaction (positive or negative) between the chemotherapy and tamoxifen, i.e. the effect in the adjuvant context of the simultaneous administration was not known. The GEICAM 9401 study (with results coincident to those of the North American Intergroup) showed that the concomitant use of tamoxifen and adjuvant chemotherapy with anthracyclines was deleterious for the patients and which translated into an increase of $5 \%$ in the absolute rate of relapse. This study, which contributed to a change in the consensus clinical practice, did not involve any extra cost to the PHS since the drugs used were those routinely administered for this indication. The GEICAM 9903 trial $^{4}$ compared the concomitant versus sequential administration of adriamycin and taxoterre in metastatic breast cancer. The sequential administration of 
the drugs resulted in much less toxicity than the concomitant, particularly in terms of febrile neutropenia, and without a reduction in the therapeutic efficacy. Again, this study which undoubtedly contributed to a change in clinical practice, caused no extra cost to the PHS since the drugs had been approved for the indication and was in routine use. These two studies, the results of which will benefit many future patients in Spain and other countries, would never have been conducted under the Directive $2001 / 20 / \mathrm{CE}$, in its present form since it states that all the cost of the drugs in the trial must be borne by the sponsor, together with the costs of insurance, labelling of the product, as well as the monitoring and management of all the medications involved in addition to the expensive task of registering and of communicating the adverse effects. Co-operative Groups and Independent Investigators (described in more pompous terms as "Academia») perform an important job in clinical investigation, and which is complementary to that performed by the Pharmaceutical Industry. In the year 2001, for example, $46 \%$ of the clinical trials in Oncology performed by Co-operative Groups in Spain were sponsored by the Co-operative Groups themselves ${ }^{5}$. Many academic studies that have changed standard clinical practice in Oncology would never had been sponsored by Industry, because the hypothesis of the work would lack commercial interest or, even, be prejudicial to its commercial interest. A classic example is the «head to head» comparison of two products approved for the same indication (strategic studies). It would seem that academia can only conduct one really neutral study if it is to be absolutely independent of the Pharmaceutical Industry. This brings us to the nub of the problem: the financing of research conducted in academia. The European Directive demands certain requirements that are very costly for the conduct of clinical trials but, in contrast to the USA, the administrations of the European Countries have not contemplated any mode of regular financing for academia-conducted studies. When, in the past few years, some Spanish Co-operative Groups have solicited public funds (for example, from the Social Security Research Fund; Fondo de Investigaciones de la Seguridad Social, FISS), their denigration has been systematic and the justification has been really surprising i.e. public funds are to help basic research and that clinical investigators should apply to the Pharmaceutical Industry for funds for their clinical trials. It seems pointless to highlight that the Pharmaceutical Industry never provides funds for projects that are not in its best interest and certainly not for those that could be clearly prejudicial. We need to reflect, here, that the Spanish Administration appears not to understand this.

The near future will be characterised, as such, by an exponential increase in the requirements and costs of clinical investigation and an absolute absence of public funds. By implementing this Directive in its current form without simultaneously resolving the problem of public funding of independent research, the European Community will be committing an error of historic proportions. Europe in general, and Spain in particular, could become the poor relation of the international clinical investigation community. We feel that the time has arrived to conduct a serious debate in the heart of the European Community and of its member states on the value, independent clinical research, its discriminative regulation and, by implication, its funding.

\section{References}

1. Directiva 2001/20/CE del Parlamento Europeo y del Consejo de 4 de abril de 2001 relativa a la aproximación de las disposiciones legales, reglamentarias y administrativas de los Estados miembros sobre la aplicación de buenas prácticas clínicas en la realización de ensayos clínicos de medicamentos de uso humano. Diario Oficial de las Comunidades Europeas L121/34 (1.5.2001).

2. Mahillo Ramos E. Implementation of directive 2001/20 in Spain: a historical opportunity for clinical research sponsored by cooperative groups. Rev Oncol 2003;5(9): 537-44

3. Pico C, Martin M, Jara C, et al. Epirubicin-cyclophosphamide (EC) adjuvant chemotherapy plus tamoxifen (TAM) administered concurrently versus sequentially: randomized phase III trial in postmenopausal node-positive breast cancer patients. A GEICAM 9401 Study [en prensa]. Ann Oncol.

4. Alba E, Martín M, Ramos M, et al. Multicenter phase III randomized trial comparing sequential versus concomitant administration of doxorubicin (A) and docetaxel (T) as first-line treatment of metastatic breast cancer (MBC). GEICAM 9903 Study [abstract 27]. Proceedings of ASCO 2003;22.

5. Mahillo Ramos E, Felip E, Baselga J, et al. Impacto de la Directiva Europea 2001/20/CE sobre ensayos clínicos en la investigación promovida por grupos cooperativos oncológicos españoles [abstract 8]. V Congreso Nacional de Medicina Farmacéutica 2002.
Miguel Martín Presidente de GEICAM 